\title{
Ciências Humanas e Sociais na formação das primeiras enfermeiras cariocas e paulistanas
}

\author{
Human and Social Sciences in the training of the first nurses 'cariocas' and 'paulistanas'
}

Ciencias Humanas y Sociales en la formación de las primeras enfermeras cariocas y paulistas

\author{
Aline Corrêa de Araújo', Maria Cristina Sanna" \\ ' Universidade Federal de São Paulo, Hospital São Paulo. Escola Paulista de Enfermagem, Grupo de Estudos e \\ Pesquisa em Administração de Serviços de Saúde e Gerenciamento de Enfermagem, \\ e Núcleo de Estudos e Pesquisas sobre Saúde, Políticas Públicas e Sociais. São Paulo-SP, Brasil. \\ "Universidade Federal de São Paulo, Escola Paulista de Enfermagem, Grupo de Estudos e Pesquisa \\ em Administração de Serviços de Saúde e Gerenciamento de Enfermagem. São Paulo-SP, Brasil.
}

Submissão: 21-01-2010 Aprovação: 25-10-2010

\section{RESUMO}

Este estudo, de natureza histórico-documental, teve como objetivo descrever e analisar o lugar que as Ciências Humanas e Sociais ocuparam no primeiro currículo escolar dos cursos de nível superior de enfermagem da Escola de Enfermagem Anna Nery (EEAN) e da Escola de Enfermeiras do Hospital São Paulo (EEHSP), identificando suas semelhanças e diferenças. Como metodologia foram analisados os currículos das referidas escolas, comparando-os e buscando entre fontes primárias e secundárias informações sobre a contribuição das Ciências Humanas e Sociais na formação das enfermeiras pioneiras da enfermagem moderna no Brasil. Concluiu-se que as matérias de humanidades ocuparam lugar secundário nos currículos estudados em comparação com as disciplinas técnicas e o aspecto utilitário que a profissão exigia na época.

Descritores: Escolas de Enfermagem; História da Enfermagem; Currículo; Educação

\begin{abstract}
This historical and documental study aimed to describe and analyze the place that the Human and Social Sciences occupied in the first curriculum of the Anna Nery Nursing School (EEAN) and of the São Paulo Hospital Nursing School (EEHSP), identifying the similarities and differences between them. As a methodology, the curricula of these schools were analyzed by comparing them and seeking, between primary and secondary sources, information of the contribution of Human and Social Sciences in the training of pioneer nurses in modern nursing in Brazil. It was concluded that the humanities subjects occupied a secondary place in the studied curricula in comparison with the technical disciplines and the utilitarian aspect required by this profession at that time.
\end{abstract}

Key words: Nursing Schools; Nursing History; Curriculum; Education

\section{RESUMEN}

Este estudio, de carácter histórico y documental, tuvo por objeto describir y analizar el lugar que las Ciencias Humanas y Sociales ocuparan en el primer programa de estudios universitarios en la Escuela de Enfermería Anna Nery (EEAN) y Escuela de Enfermeras del Hospital São Paulo (EEHSP), identificando las semejanzas y diferencias entre ellos. Se analizó los planes de estudio de estas escuelas, comparándolos y buscando, entre las fuentes primarias y secundarias, la contribución de las Ciencias Humanas y Sociales en la formación de enfermeras pioneras de la enfermería moderna en Brasil. Se concluyó que los temas de humanidades, el segundo lugar en el currículo de estudios en comparación con las técnicas y el aspecto utilitario que la profesión requerida en el momento.

Palabras clave: Escuelas de Enfermería; Historia de Enfermería; Currículo; Educación

Trabalho realizado como exigência para aprovação na Disciplina de História da Administração em Enfermagem, Programa de Pós-Graduação stricto sensu, Departamento de Enfermagem da Unifesp. 


\section{INTRODUÇÃO}

Florence Nightingale inaugurou a Enfermagem Moderna com a fundação da Escola do Hospital Saint Thomas em 1860, e com o livro Notas Sobre a Enfermagem, publicado em 1859, apresentando seu modelo de ensino de enfermagem vinculado ao âmbito hospitalar e valorizando a experiência prática. Nessa escola era exigido o ensinamento teórico sistematizado, com autonomia financeira e pedagógica; e recomendava-se que as escolas que seguissem esse modelo fossem dirigidas por enfermeiras. Também se preocupava com o comportamento pessoal das alunas e sua postura física e vestimentas, em função da valorização do trabalho da enfermeira que, após a Reforma Protestante passou a ser exercida por mulheres de moral duvidosa. O modelo propunha ainda a divisão social do trabalho por meio da distinção de funções entre as "nurses", com atividades usuais no hospital, e as "ladies nurses", com atividades mais elaboradas de supervisão da assistência, administração e ensino ${ }^{(1)}$.

Sob esse ideário se compôs a Enfermagem no Brasil, mais especificamente no Rio de Janeiro, na Escola de Enfermagem Anna Nery (EEAN), que iniciou suas atividades em 1923, por iniciativa do diretor geral do Departamento Nacional de Saúde Pública da época, o sanitarista Carlos Chagas, com a cooperação do Serviço Internacional de Saúde da Fundação Rockefeller por meio da Missão Técnica de Cooperação para o Desenvolvimento da Enfermagem no Brasil(2).

A Missão Parsons, como ficou conhecida, por conta da liderança de Ethel O. Parsons, organizou um Serviço de Enfermeiras de Saúde Pública e foi formada por enfermeiras americanas que chegaram ao Rio de Janeiro em dois de setembro de 1921 e seguiram o modelo de ensino e de prática da enfermagem moderna, segundo os princípios norteadores do sistema nightingaleano reinterpretado pelas americanas, o chamado modelo anglo-americano de formação. A escola iniciou o curso com 13 alunas, em regime integral de atividades, por um período de 28 meses inicialmente ${ }^{(3)}$.

Aproximadamente dezesseis anos depois, na cidade de São Paulo, foi inaugurada, em primeiro de março de 1939, a Escola de Enfermeiras do Hospital São Paulo (EEHSP), um dos pioneiros cursos de formação de enfermeiras no modelo citado na cidade e que foi instituído pela Escola Paulista de Medicina (EPM) com o intuito de servir às suas próprias exigências, garantindo qualidade técnica ao serviço assistencial, segundo o padrão* da Escola de Enfermagem Anna Nery. Também sob o regime de internato, como da escola padrão, inicialmente o curso tinha a duração de dois anos e quatro meses, que logo se estenderia para três anos, com 15 dias de férias anuais ${ }^{(4)}$.

Para tanto, o arcebispo paulistano, Dom José Gaspar de Affonseca, contratou madres francesas da Congregação Franciscanas Missionárias de Maria para dirigir a Escola, que teve a orientação científica dos professores da EPM, não fugindo, assim, à orientação filosófica e caritativa do nascimento da Enfermagem em qualquer outro lugar do mundo ocidental. $\mathrm{O}$ lema instituído para a Escola foi "Non vivere nisi ad serviendum" (Não viver senão para servir), imprimindo a prioridade da assistência e recomendando a subserviência, com o aspecto religioso enraizado na rigidez profissional. Na primeira turma formaram-se cinco enfermeiras ${ }^{(4)}$.

Ainda no contexto histórico, registra-se que o nascimento da Enfermagem Moderna no Brasil foi permeado por importantes marcos. Iniciou-se oficialmente num período pós $1^{\text {a }}$ Guerra Mundial, quando ainda se sentia os efeitos da Proclamação da República, com seus primórdios de modernização e industrialização no país e no ápice do desenvolvimento do movimento sanitarista e higienista na saúde. Esse enfrentou rejeição por meio de revoltas e manifestações de notória insatisfação com as mudanças sócio-políticas e econômicas que, posteriormente, se exprimiram, inclusive, em amostras culturais, como a conhecida Semana de Arte Moderna em 1922, quando artistas se reuniram no importante e tradicional Teatro Municipal de São Paulo, para propor renovação artística, cultural, social e política, para que o país assumisse identidade legitimamente nacional.

A Saúde, nesse contexto, representava o atraso na medida em que as ciências e a tecnologia nesse campo requeriam instituições prestadoras de assistência melhor estruturadas e sua intervenção garantia sustentação para o modelo econômico, na medida em que melhorava o saneamento das grandes cidades e preservava a força de trabalho urbana industrial. Por esse motivo a criação de escolas de enfermagem nos centros mais desenvolvidos do país não pode ser considerada iniciativa isolada. Sua concretização integrava projeto maior de avanço em direção à almejada modernização.

Quando a EEHSP nasceu, após a Revolução Constitucionalista de 1932 protagonizada por São Paulo e imediatamente próxima ao início da $2^{\mathrm{a}}$ Guerra Mundial, São Paulo era o berço do desenvolvimento industrial, gerido sob a pressão do movimento operário e sob a forte influência do empresariado para quem a mão-de-obra era valiosa. Essa conjuntura era favorável ao desenvolvimento da assistência curativa, individual e, portanto, dependente da criação, instalação e operação de hospitais, o que demandava pessoal de enfermagem, razão para a criação da escola.

Esse clima revolucionário em que surgiram as duas escolas porém, contraditoriamente, não influenciou o ideário de ambas, já que a formação que nelas se praticava teve um caráter conservador e reacionário e, em última análise, positivista, como declarado por alguns autores. ${ }^{(5)}$

O surgimento da EEAN veio ao encontro dos interesses políticos e econômicos da nova ordem republicana que, balizada nos princípios liberais, e embora politicamente excludente, defendia a universalização de certos benefícios como

* A regulamentação do ensino da enfermagem no Brasil definido pelo decreto $n^{\circ} 20.109$ de 15/06/1931, fixou as condições para a equiparação das escolas. O título de enfermeira diplomada só era reconhecido depois de registrado no Departamento Nacional de Saúde Pública, ao qual a Escola de Enfermeiras D. Anna Nery estava subordinada, e que, por esse decreto foi considerada como escola oficial padrão. Todas as escolas que quisessem formar enfermeiros deveriam se equiparar e solicitar reconhecimento dessa condição àquele órgão federal. 
a assistência à saúde e a educação básica(6). A partir de então, a saúde passou a ser vista como responsabilidade do Estado, garantindo a política agroexportadora, de imigração e da urbanização e, por causa disso, as políticas públicas de saúde à época, com sua postura nitidamente higienista, se encaminharam para o controle de endemias e para o saneamento das cidades, evidenciando a intenção de propiciar condições sanitárias adequadas ao desenvolvimento capitalista ${ }^{(7)}$.

Na criação do curso da EEHSP, entre os anos de 1930 e 1940, houve forte influência da elite conservadora paulistana, que se preocupou em formar enfermeiras nos moldes oficiais e com inclinação pessoal para a profissão ${ }^{(4)}$. O momento era de notório crescimento da industrialização no Brasil, tendo o Ministério da Educação passado a investir no preparo do cidadão para diversas ocupações ${ }^{(8)}$ utilizando-se do ensino como instrumento de produção do conhecimento demandado pelas necessidades econômicas vigentes.

Ambas escolas de enfermagem foram idealizadas para auxiliar a prática médica, a primeira dando continuidade às atividades educativas de higiene e prevenção de endemias iniciadas por médicos sanitaristas ${ }^{(9)}$ e a segunda para prover a assistência com qualidade técnica no hospital da Escola Paulista de Medicina $^{(4)}$. Além disso, cada uma delas procurava responder às demandas sociais de então. A formação da enfermeira, nessa perspectiva, poderia incluir algum preparo para a compreensão dessa dimensão, a fim de bem desenvolver o seu trabalho, indagação que gerou a realização do presente estudo.

Nessa direção, a intenção é buscar algum vestígio, na formação dessas enfermeiras, de preocupação e de responsabilidade em relação à sua formação sócio humanística. Com tal finalidade, serão analisados o primeiro currículo das duas escolas de modelo anglo-americano, formadoras das enfermeiras pioneiras das cidades do Rio de Janeiro e São Paulo, atentando-se para os conteúdos relacionados às Ciências Humanas e Sociais constantes na grade curricular.

A escolha das escolas dos dois grandes centros econômicos da época se justifica porque o projeto de desenvolvimento para o país incluía a já citada ação no campo da Saúde. Pode-se objetar que a Escola Carlos Chagas de Minas Gerais, fundada antes da EEHSP, seria modelo de influência da religião católica mais que esta, mas, não se pode esquecer que a direção da EEHSP desempenhou papel preponderante, na representação oficial da Igreja Católica, nas entidades de classe, em comparação com a escola mineira, se mais não for, pelo fato de ser liderada por religiosas vinculadas a congregações formalmente instituídas.

Registre-se que, quando a EEHSP foi concebida, o decreto $n^{\circ}$ 20.109/31, que estabelecia o ensino praticado na EEAN como padrão para todo país, era vigente mas, a organização curricular na disposição das disciplinas era decidida em cada escola, o que torna possível indagar sobre esse aspecto.

Por definição, as Ciências Humanas são as disciplinas cujo objeto exclusivo é o homem em suas várias dimensões ${ }^{(10)} \mathrm{e}$, segundo a classificação do CNPq/CAPES são compostas por: Filosofia, Sociologia, Antropologia, Arqueologia, História, História do Conhecimento, Geografia, Psicologia, Educação, Ciência Política, Relações Internacionais e Teologia. Já Ciências
Sociais são o conjunto de disciplinas que estudam o homem através das suas relações com a sociedade e com a cultura ${ }^{(11))}$. Essa classificação da CAPES é atual e não se dispunha de tantas disciplinas no ensino formal brasileiro à época. No entanto, os conteúdos a que essas se referem já existiam, e a apropriação desses conhecimentos pelos enfermeiros Ihes permitiria compreender a dimensão do cuidar humano, de pessoa para pessoa, das relações entre os humanos que estão envolvidos nesse fazer, o que inclui o indivíduo que cuida, individualmente e tomado em grupos e coletividades de profissionais, e do indivíduo e grupos que são cuidados, representados pela família, outros grupos sociais, comunidades e coletividades.

Por que o interesse pelas Ciências Humanas e Sociais? Partindo do pressuposto de que a Educação é capaz de formar sujeitos críticos, com autonomia e cidadania é que se justifica a realização do presente trabalho, pois, analisando-se a importância dada às Ciências Humanas e Sociais nos seus primeiros currículos e pensando nesse conteúdo como um instrumento que permite a compreensão, reflexão e analise do comportamento humano e seu entorno próximo, necessárias ao bom desenvolvimento do trabalho do enfermeiro, pode-se identificar qual a abordagem dedicada a esse aspecto por ambas escolas em foco.

\section{OBJETIVO}

Descrever o lugar que as Ciências Humanas e Sociais ocuparam no primeiro currículo escolar dos cursos de nível superior de enfermagem das escolas EEAN e EEHSP;

Identificar as semelhanças e as diferenças no tratamento das Ciências Humanas e Sociais nos currículos das escolas EEAN e EEHSP.

\section{MÉTODO}

Pesquisa histórico-documental que utilizou, como fontes primárias, os primeiros currículos escolares praticados pela EEAN e pela EEHSP e o currículo da EEAN à época da criação da EEHSP e, como fontes secundárias, artigos, livros e teses com temas afins.

O primeiro currículo da Escola de Enfermagem do Departamento Nacional de Saúde Pública, em 1923, que posteriormente se denominou EEAN, baseou-se no "Standard Curriculum School of Nursing", em vigor nos EUA desde $1917^{(12)}$. O primeiro currículo da EEHSP, por sua vez, seguiu os moldes da Escola Padrão EEAN, oficial no Brasil, desde 1931 e tal como era praticado em 1939; portanto, para não cometer anacronismo comparando a grade curricular de escolas que iniciaram suas atividades com dezesseis anos de diferença, optou-se por fazê-lo empregando-se o currículo da EEAN vigente no ano de 1939.

As cópias de currículos da EEAN foram obtidas, respectivamente, o primeiro da tese de Porto, 1997, e o praticado à época de criação da EEHSP de dois históricos escolares, obtido junto ao Centro de Documentação da EEAN/UFRJ.

A cópia do currículo da EEHSP foi obtida junto à Reitoria da Unifesp, no Histórico da Escola de Enfermeiras do Hospital 
São Paulo e, para complementação de informações sobre carga horária, este foi cotejado com o artigo extraído da dissertação de Mestrado Ensino em Ciências da Saúde da Unifesp.

A análise dos currículos buscou, no primeiro momento, elencar as disciplinas com conteúdo relacionado às Ciências Humanas e Sociais, o ano de sua inserção e sua carga horária e observá-las no contexto de cada currículo, para identificação de seu status em cada um desses. Em seguida compararam-se os currículos da EEAN entre si, para identificar as mudanças ocorridas nos três lustros que separavam o oferecimento de um e outro. Por fim, os currículos contemporâneos de ambas escolas foram comparados para identificação de semelhanças e diferenças entre eles, em relação às disciplinas foco do estudo.

\section{RESULTADOS E DISCUSSÃO}

Houve mudanças nos dois currículos da EEAN analisados, com a redistribuição de disciplinas: técnica de enfermagem, patologia interna e externa, enfermagem em patologia interna e externa, técnica adiantada, doenças contagiosas, enfermagem em doenças contagiosas, enfermagem obstétrica, enfermagem em pediatria, técnica de sala operatória, enfermagem em primeiros socorros, enfermagem em oftalmologia, enfermagem em ORL; a exclusão de algumas: ortopedia, ginecologia, problemas sociais, serviço social, serviço privado, enfermagem industrial, doenças especiais; a inclusão de outras: ética, canto coral, ginástica, higiene em saúde pública, enfermagem em saúde pública, higiene escolar, pedagogia aplicada à enfermagem e a mudança na denominação das disciplinas: dietética, ouvido nariz e garganta, olhos, bandagens, doenças cirúrgicas, doenças comunicáveis, doenças da criança, doenças mentais e nervosas, doenças ocupacionais venéreas e de pele; como se pode ver na Figura 1, um quadro comparativo das três grades curriculares das duas escolas. Entretanto, as mudanças não configuraram a proposição de outro currículo, guardando semelhanças entre si no que diz respeito à sua estrutura e composição.

As disciplinas do curso da EEAN, em 1939, eram divididas em séries, a primeira era chamada de Série Preliminar, seguida da Segunda Série Júnior, Terceira Série Intermediária e finalmente Quarta Série Sênior. Já as Disciplinas da EEHSP, ainda que não tivessem a mesma denominação não se apresentaram de maneira muito diferente, haja vista a obrigatoriedade de seguir o padrão da escola oficial, ainda que até a terceira turma tivesse 28 meses de curso, passando em seguida para 36 meses como o da EEAN.

O curso de ambas as Escolas era repleto de disciplinas técnicas e instrumentais focadas na prática de enfermagem, com ênfase para o aspecto biológico, em suas diversas dimensões. Dentre as que se dedicavam ao conteúdo de Ciências Humanas, encontrou-se, na EEAN: História de Enfermagem e Ética na primeira série e, somente na última série, mais duas denominadas Problemas Profissionais e Pedagogia aplicada à Enfermagem. Infelizmente não foi possível, com as informações capturadas determinar a carga horária exata das disciplinas praticada nesse ano, mas supõe-se que não tenha fugido muito do seu primeiro currículo, no qual 50 horas foram destinadas às disciplinas de Ciências Humanas. Na EEHSP, no primeiro período, as disciplinas são idênticas às da EEAN, com História da Enfermagem (55 horas) e Ética (81 horas), aí se encerrando as disciplinas que se dedicavam ao conteúdo de Ciências Humanas.

Como já explicitado eram escolas de regime de internato com cerca de doze horas diárias de atividades, em 36 meses; portanto, as cento e trinta e seis horas dedicadas às Ciências Humanas, em todo curso da EEHSP, são evidência da pouca importância atribuída ao ensino formal desse conteúdo, já que o total de aulas teóricas somavam 2182 horas. Ocorre que a formação da enfermeira, nesse regime, também incluía atividades sociais e de lazer que poderiam acrescentar aproximação a temas afetos a essas disciplinas por meio de leituras e eventualmente, freqüência a cinemas, teatros e outras manifestações culturais semelhantes. Não se descarta ainda a possibilidade do conteúdo dessas disciplinas ser abordado nas disciplinas que ensinavam a cuidar. Independente dessas variações a exigüidade da carga horária destinada as disciplinas em foco no presente trabalho são uma medida da pouca valorização das ciências humanas sociais em comparação com os demais componentes curriculares.

Ao fazer ilações sobre as razões dessa distribuição para elaboração do primeiro currículo da EEHSP, levantou-se a hipótese de que talvez houvesse dificuldades na sua formulação porque o mesmo obedeceu a duas orientações - o modelo da escola padrão e dos professores da Escola Paulista de Medicina e médicos do HSP, fundadores da escola. Não se percebeu, nas fontes primárias e secundárias consultadas, que houvesse dificuldades entre os últimos e as religiosas que dirigiam e lecionavam na escola, mas chamou à atenção declaração de um desses médicos sobre o que esperavam das enfermeiras que ali seriam formadas.

Octávio de Carvalho, médico fundador e primeiro diretor da EPM, em carta endereçada a Álvaro Guimarães Filho, também médico fundador da escola, demonstrava sua preocupação quanto à qualidade de enfermeira que seria formada na nova escola e ressaltava a suprema importância da formação moral das alunas, antes mesmo do conhecimento técnico científico (que dirá político!). Em justificativa dizia que, ao formarem enfermeiras do nível da EEAN, o hospital da EPM, ou não se conseguiria pagar por seus serviços, ou muito provavelmente elas se casariam com médicos ${ }^{(13)} \mathrm{e}$, por esse motivo, as enfermeiras formadas nessa escola deveriam ter comportamento exemplar, obediência e boa técnica, para que permanecessem servindo exclusivamente ao Hospital São Paulo após a conclusão do curso.

Madre Domineuc, que foi diretora da EEHSP também valorizava a qualificação moral das estudantes, possivelmente por outros motivos, além dos apontados por Octávio de Carvalho, certa vez lamentou o baixo nível de instrução das alunas que ingressavam no curso, já que não era exigido o ensino secundário (curso fundamental) inicialmente ou até a equiparação oficial com a escola padrão, e eram aceitas candidatas que atestassem experiência anterior em serviço na área da saúde ou fizessem uma prova avaliada por três professores da escola. 


\begin{tabular}{|c|c|c|c|c|c|c|}
\hline \multirow[b]{2}{*}{ Série } & \multicolumn{2}{|l|}{ EEAN } & \multicolumn{2}{|l|}{ EEAN 1939} & \multicolumn{2}{|l|}{ EEHSP } \\
\hline & Disciplina & $\begin{array}{c}\text { Carga } \\
\text { horária } \\
\text { (horas) }\end{array}$ & Disciplina & $\begin{array}{c}\text { Carga } \\
\text { horária } \\
\text { (horas) }\end{array}$ & Disciplina & $\begin{array}{c}\text { Carga } \\
\text { horária } \\
\text { (horas) }\end{array}$ \\
\hline \multirow{13}{*}{ 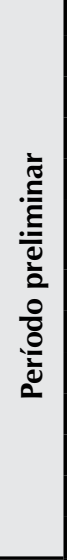 } & Princípios de Física, Química, Anatomia e Fisiologia & 50 & Anatomia e Fisiologia & & Anatomia & 302 \\
\hline & Teoria e Prática de Bacteriologia & 45 & Microbiologia & & Bacteriologia & 128 \\
\hline & Dietética & 30 & Nutrição & & Nutrição & 127 \\
\hline & Ouvido, Nariz e Garganta & 8 & Técnica de Enfermagem & & Técnica de Enfermagem & 345 \\
\hline & Drogas e Soluções & 20 & Drogas e Soluções & & Drogas & 79 \\
\hline & $\begin{array}{l}\text { Princípios e Métodos de Enfermagem e Higiene } \\
\text { Pessoal }\end{array}$ & 45 & Higiene & & Higiene Individual & 51 \\
\hline & Olhos & 8 & Química Aplicada & & Química Aplicada & 183 \\
\hline & História da Enfermagem & 20 & História da Enfermagem & & História da Enfermagem & 55 \\
\hline & Massagem & 10 & Ética & & Ética & 81 \\
\hline & Primeiros Socorros & 10 & Ginástica & & Ginástica & 105 \\
\hline & Bandagens & 10 & Ataduras & & Ataduras & 72 \\
\hline & Enfermagem Prática & 45 & Estágio Prático & & Estágio Prático no Hospital & 420 \\
\hline & & & Canto Coral & & & \\
\hline \multirow{12}{*}{$\begin{array}{l}\stackrel{0}{c} \\
\text { స } \\
\stackrel{-}{-}\end{array}$} & Patologia Elementar e Doenças Médicas & 30 & Patologia Geral & & Patologia Geral & 19 \\
\hline & Doenças Cirúrgicas & 20 & Patologia Interna & & Patologia Interna & 80 \\
\hline & Doenças Comunicáveis & 15 & Patologia Externa & & Patologia Externa & 60 \\
\hline & Doenças da Criança & 20 & Enfermagem em Patologia Interna & & Enfermagem em Patologia Interna & 26 \\
\hline & Tuberculose & 15 & Enfermagem em Patologia Externa & & Enfermagem em Patologia Externa & 37 \\
\hline & Matéria Médica & 20 & Matéria Médica & & Matéria Médica & 37 \\
\hline & Ortopedia & 10 & Higiene Mental & & Higiene Mental & 53 \\
\hline & Dietética & 50 & Dietética Aplicada & & Dietética & 8 \\
\hline & Obstetrícia e Ginecologia & 25 & Massagem & & Massagem & 20 \\
\hline & & & Técnica Adiantada & & Ginástica & 88 \\
\hline & & & Estágio Prático & & Estágio Prático no Hospital & 1448 \\
\hline & & & Obstetrícia & & & \\
\hline \multirow{11}{*}{$\begin{array}{l}\stackrel{0}{\frac{D}{\sigma}} \\
\text { ปे }\end{array}$} & Doenças Mentais e Nervosas & 20 & Doenças Contagiosas & & Doenças Infecto-contagiosas & 6 \\
\hline & Doenças Ocupacionais, Venéreas e de Pele & 10 & Enfermagem em Doenças Contagiosas & & Enfermagem em Doenças Infecto-contagiosas & 11 \\
\hline & Terapêuticas Especiais & 10 & Obstetrícia & & Obstetrícia Normal & 49 \\
\hline & Problemas Sociais & 10 & Enfermagem Obstétrica & & Enfermagem Obstétrica & 10 \\
\hline & Revisão Geral de Enfermagem & 10 & Pediatria & & Pediatria & 44 \\
\hline & Problemas Profissionais & 10 & Enfermagem em Pediatria & & Ginecologia & 23 \\
\hline & Serviço Social & 10 & Técnica de Sala Operatória & & Técnica de Sala Operatória & 5 \\
\hline & Primeiros Socorros e Emergência & 10 & Primeiros Socorros & & Ginástica & 70 \\
\hline & Serviços Privados & 10 & Estágio Prático & & Estágio Prático no Hospital & 1148 \\
\hline & Enfermagem Industrial & 10 & Dietética Infantil & & & \\
\hline & Doenças Especiais & 10 & Enfermagem em Primeiros Socorros & & & \\
\hline \multirow{15}{*}{$\begin{array}{l}\text { 을 } \\
\text { in }\end{array}$} & & & Problemas Profissionais & & & \\
\hline & & & Doenças Venéreas & & & \\
\hline & & & Tuberculose & & & \\
\hline & & & Oftalmologia & & & \\
\hline & & & Enfermagem em Oftalmologia & & & \\
\hline & & & ORL & & & \\
\hline & & & Enfermagem em ORL & & & \\
\hline & & & Higiene em Saúde Pública & & & \\
\hline & & & Enfermagem em Saúde Pública & & & \\
\hline & & & Enfermagem Aperfeiçoada & & & \\
\hline & & & Psiquiatria & & & \\
\hline & & & Enfermagem em Psiquiatria & & & \\
\hline & & & Higiene Escolar & & & \\
\hline & & & Pedagogia Aplicada à Enfermagem & & & \\
\hline & & & Estágio Prático & & & \\
\hline
\end{tabular}

Figura1 - Currículos das Escolas de Enfermagem Anna Nery e de Enfermeiras do Hospital São Paulo 
Para solucionar tal situação, ficou acordado que o regime de internato ajudaria a reparar o "defeito de educação" das alunas matriculadas, além de círculos de estudos sobre ética e cultura geral, pedagogia especial com círculos de estudo para elaboração de pontos, interrogação com atribuição de notas e, por fim, se fosse necessário, eliminação das incapa$z s^{(14)}$. Isso faz supor que havia outras atividades de ensino que iam além do currículo oficial, o que se costuma designar por currículo oculto ${ }^{(15)}$. A existência do internato facilitava a inclusão dessa complementação, posto que as alunas ficavam permanentemente na escola, a qual habitavam coletivamente, juntamente com grande parte do corpo docente.

Já o curso da EEAN embora também tivesse uma carga horária de prática bastante superior à teórica, aceitava preferencialmente candidatas com habilitação em curso normal ou o equivalente, e ainda havia uma movimentação das enfermeiras orientadoras do curso e das estudantes com o propósito de se criar um projeto político que elevasse o padrão da profissão ${ }^{(16)}$, com embasamento teórico, criticidade e grande influência da enfermagem norte-americana. Um exemplo patente dessa orientação para a prática política por meio da representação corporativa organizada foi a criação da Associação Nacional de Enfermeiras Diplomadas Brasileiras (ANEDB) pelas enfermeiras formadas na primeira turma da EEAN, que posteriormente se tornou na Associação Brasileira de Enfermagem (ABEn), desde então e até hoje, o órgão mais representativo da Enfermagem brasileira. Esse fato faz indagar sobre a competência política e a conseqüente formação humanística e social das alunas e docentes da EEAN. Saliente-se, porém, que a criação da associação se deu por orientação americana via corpo docente da escola e foi mantida pela inspiração advinda das discípulas de Lilian Clayton, líder no Teacher 's College da Universidade de Columbia, onde parte das primeiras professoras brasileiras fizeram seus estudos pós graduados. Assim, não apenas a formação humanística e social obtida no curso como a já trazida do curso normal e, principalmente, o modelo referência americano e o ambiente de convivência na EEAN podem ter sido os principais responsáveis pela criação do órgão de representação.

Voltando às disciplinas, é interessante notar que História da Enfermagem, nas duas escolas, além de ser apresentada com o mesmo nome, foi ministrada no curso preliminar. Possivelmente essa disciplina tinha a intenção de inserir a aluna na cultura da Escola e da profissão, que experimentava grandes transformações, o que talvez não fosse percebido por elas. Não se sabe o que efetivamente foi ensinado, mas, provavelmente, a julgar pelos livros-texto datados da época disponíveis nas bibliotecas de ambas escolas ainda hoje, a disciplina deve ter sido utilizada como instrumento para a formação da identidade profissional, para desenvolver um compromisso com a profissão, para melhor inserção da profissão na sociedade ${ }^{(17)}$, inicialmente, acreditamos ainda que devem ter discutido a profissionalização da enfermagem e o que isso representava para as enfermeiras brasileiras naquele momento.

Ainda no curso preliminar, as escolas ministraram a disciplina de Ética, que deve ter permitido a ampla divulgação dos valores morais que eram defendidos pela Enfermagem de então. Em que pese o fato da EEAN ter sido criada com a intenção de formar enfermeiras de Saúde Pública, as mudanças observadas no currículo, em 1939, indicam que Ética veio substituir duas outras ministradas no primeiro formato praticado pela escola - Problemas Sociais e Serviço Social. Além disso, como se vê no quadro comparativo, houve deslocamento da ênfase para o ensino do cuidado curativo e hospitalar.

De fato a partir dos anos 1940, o número de hospitais começou a crescer, principalmente no Rio de Janeiro e São Paulo, com a medicalização do corpo e a preocupação com a recuperação da força de trabalho operária. Nas duas cidades citadas, instituições hospitalares modelares, ligadas a faculdades de medicina ou criadas pela previdência social, primeiro através das caixas de pensões e aposentadorias e depois pelo ministério próprio, alavancaram o modelo biomédico de prestação de assistência à saúde, que prosperaria no período da Ditadura Militar com financiamento previdenciário de hospitais particulares, até seu esgotamento, com a Reforma Sanitária. Essa conformação influenciou o ensino de enfermagem desde a lei no. 775/49 até o currículo mínimo de 1994.

$\mathrm{Na}$ EEHSP, que iniciou suas atividades com o currículo voltado a formar enfermeiras para trabalharem naquele hospital, suspeita-se que a importância dada à condição moral, certamente abordada na disciplina de Ética, albergava também razões práticas, como a fidelização das formandas, favorecendo o estabelecimento de um contrato, ainda que tácito, com os padrões anteriormente descritos por seus dirigentes e desejáveis para as futuras enfermeiras do hospital que dava nome à escola.

As disciplinas com conteúdo de Ciências Humanas e Sociais, na EEHSP findaram logo no curso preliminar, pela grade curricular oficial, mas a escola também oferecia cursos extracurriculares como Geografia Econômica, Geografia Humana, História das Civilizações, História das Artes, História da Filosofia, Religião, e algumas atividades culturais ${ }^{(4)}$ aparentando preocupação com o aporte cultural geral das estudantes e sua formação social e humanista ao longo do curso.

Como se vê na figura 1, no último ano do curso da EEAN, eram ministradas as disciplinas Problemas Sociais e Pedagogia aplicada à Enfermagem. Considerando que as egressas daquela escola eram absorvidas em funções de liderança no próprio sistema público de saúde ou iam dirigir outras escolas de enfermagem, é compreensível que necessitassem de formação específica. Além disso, a localização dessas disciplinas no final do curso sugere serem um último lembrete à concluinte, que foi preparada para atuar extra-muros da escola, da necessidade de manter o compromisso com o entorno próximo aos seus futuros postos de trabalho, sem, contudo, deixar de se preocupar com o desenvolvimento da profissão.

\section{CONSIDERAÇÕES FINAIS}

Ao analisar os currículos praticados no início de funcionamento das escolas EEAN e EEHSP, percebeu-se algumas diferenças entre elas, não na grade curricular em si, mas na postura política das escolas analisadas. A carioca tinha o intuito de ampliar a enfermagem moderna no país servindo de 
escola modelo, mantendo a rígida disciplina das estudantes e, ainda assim, tinham uma postura mais vanguardista em relação à escola paulista que, por sua vez, mantinha, em relação as suas alunas, ensinamentos que as levaram a serem mais reservadas e passivas.

As Ciências Humanas ensinadas na formação das primeiras enfermeiras do modelo anglo-americano das cidades do Rio de Janeiro e São Paulo parece não terem sido consideradas de grande relevância para formação de tais enfermeiras pois, como apurado, foram ministradas em poucas horas, aparentemente a fim de cumprir o currículo, sendo bem no início ou no fim do curso, não parecendo ter a função nem de instrumentação para o trabalho assistencial, já que enfermeiras lidam com seres humanos, e muito menos para formar profissionais com prática política ativa, se percebendo cidadãs e atuando como tal.

Cabe indagar se essa reduzida valorização não carregava consigo a intencionalidade de coibir o agir com autonomia e consciência de si mesmas e de suas funções, o que parece contraditório com a proposta de formação de nível tão elevado de escolaridade, já que, se o desejado eram apenas simples instrumentadoras do cuidado, como já havia disponíveis na força de trabalho que atuava nos estabelecimentos de saúde, seria necessário apenas um pouco mais de treinamento, a fim de executarem a assistência de enfermagem, ao invés de curso tão longo. Não há resposta para essa indagação uma vez que a presente análise contemplou apenas a distribuição e carga horária das disciplinas e não o conteúdo e a forma de ensiná-lo, que precisa ser mais bem estudados para que se possa explorar essa hipótese.

Com a intenção de contribuir para a compreensão sobre o valor e o reconhecimento social da profissão, ao estudar esse capítulo da história da Enfermagem brasileira, foi possível encontrar a origem da ideologia de subserviência praticada por tantos anos, que relegou a Enfermagem a posição subalterna no trabalho em saúde. A despeito disso, a enfermagem desenvolvida na época, se deu num contexto em que a mulher ainda lutava por conquistar seu espaço na sociedade e que a partir da primeira metade do século 20 a imagem da muIher na sociedade brasileira vinha sofrendo transformações, no qual a profissão da enfermagem contribuiu no processo de emancipação da mulher, sem no entanto entrar em conflito com a ordem social vigente ${ }^{(18)}$. As enfermeiras e alunas de ambas instituições estudadas, nesse sentido desempenharam papel de vanguarda criando associações, fundando revistas, lutando por condições de trabalho, enfim ampliando a participação a participação social e política da mulher.

Assim investigaram-se indicativos de politicidade presentes nos currículos das primeiras escolas, carioca e paulista, de modelo anglo-americano, representados pela inserção de Ciências Humanas, cujo resultado demonstrou fragilidade na preparação das primeiras enfermeiras nelas formadas, em relação a esse conteúdo. Saliente-se, porém, que a análise limitou-se ao posicionamento e carga horária dessas disciplinas, sendo oportuno aprofundar, em estudos futuros, o estudo do conteúdo e das estratégias de ensino adotadas a época para certificação dessa fragilidade.

\section{AGRADECIMENTOS}

Agradecemos a algumas pessoas que nos ajudaram com informações e acessos à fontes sem o qual este estudo não seria possível - Dra Maria Angélica de Almeida Peres professora da EAAN; Márcia Regina Barros Silva e Nádia Vieira, historiadora e funcionária do Centro de História e Filosofia da UNIFESP; Maria Regina Guimarães Silva, enfermeira e mestre em Ensino em Ciências da Saúde; e Marta Costa Peñas, funcionária da Pró-Reitoria de Graduação da UNIFESP.

\section{REFERÊNCIAS}

1. Silva GB da. Enfermagem profissional: análise crítica. São Paulo: Cortez; 1986.

2. Carvalho AC. Associação Brasileira de Enfermagem. 1926 - 1976. Documentário. Brasília: ABEn; 1976.

3. Coelho CP et al. Escola de Enfermagem Anna Nery: sua história, nossas memórias. Rio de Janeiro(RJ): Cultura Médica; 1997.

4. Silva MRG, Gallian DMC. A escola de enfermagem do hospital São Paulo e seu primeiro currículo (1939-1942). Rev Bras Enferm 2009; 62 (2): 317-22.

5. Almeida AM, Oliveira ERA, Garcia TR. Pesquisa em enfermagem e o positivismo. Rev da Esc de Enf USP 1996; 30 (1): 25-32.

6. Nascimento, MEB; Oliveira, MCM. Caminhos e desafios da enfermagem no Brasil. Rev HISTEDBR [on-line] set 2006; n.23: 131-142. Disponível: http://www.histedbr. fae.unicamp.br/art09_23.pdf

7. Germano RM. Educação e Ideologia da Enfermagem no Brasil. $3^{\text {a }}$ ed. São Paulo: Cortez; 1993.

8. Pereira, I.B; Ramos, M.N. Educação profissional em saúde. Ed. FioCruz, 2006.

9. Alcântara GA. Enfermagem moderna como categoria profissional: obstáculos à sua expansão na sociedade brasileira [tese]. Ribeirão Preto (SP): Escola de Enfermagem de Ribeirão Preto, Universidade de São Paulo; 1996.

10. Durozoi G, Roussel A. Dicionário de filosofia. Tradução: Marina Appenzeller. Campinas: Papirus, 1993.

11. Maia RL (org.).Dicionário de sociologia. Porto: Porto editora, 2002.

12. Sauthier JA. A missão de enfermeira norte-americanas na capital da república: 1921-1931 [tese]. Rio de Janeiro (RJ): Escola de Enfermagem Anna Nery, Universidade 
Federal do Rio de Janeiro; 1996.

13. Silva MRB da. Estratégias da Ciência: A História da Escola Paulista de Medicina (1933-1956). São Paulo: EDUSF; 2003.

14. Escola Paulista de Medicina. Escola de Enfermagem. Histórico da Escola de Enfermeiras do Hospital São Paulo, pág. 8. São Paulo, 1939.

15. Porto IS. História da experiência de mudança curricular na graduação da Escola de Enfermagem Anna Nery: 1976 a 1982 [tese]. Rio de Janeiro (RJ): Escola de Enfermagem Anna Nery, Universidade Federal do Rio de Janeiro; 1997.
16. Cruz JLG, Marques IR. Elementos do projeto político da Associação Nacional das Enfermeiras Diplomadas Brasileiras presentes nos Annaes de Enfermagem. Rev Bras de Enferm 2006; 59(esp): 438-41.

17. Barreira I A. Memória e história para uma nova visão da enfermagem no Brasil. Rev Latino-am. Enfermagem 1999; 7 (3): 87-93.

18. Santos, T.C.F.; Barreira, I.A. A mulher e a enfermeira na nova ordem social do Estado Novo. Texto Contexto Enferm, Florianópolis, 2008 Jul-Set; 17(3): 587-93. 